\title{
Investigation of Culture Filtrate of Endophytic Fungi Nigrospora sp. Isolate RS 10 in Different Concentrations towards Root-knot Nematode Meloidogyne spp.
}

\author{
Nur Amin* \\ Department of Plant Protection, Faculty of Agriculture, Hasanuddin University, Indonesia; nuramin_62@yahoo.com
}

\begin{abstract}
One of the modes of action of endophytic fungi against plant pathogens e.g. plant parasitic nematode, is the production of toxic culture filtrate. Experiments were conducted to investigate the antagonistic effects of different concentrations of the culture filtrate produced by the endophytic fungi Nigrospora sp. isolate RS 10 against the root knot nematode Meloidogyne spp. Nigrospora sp. isolate RS 10 was isolated from the healthy root of a sengon plant (Paraserianthes falcataria). Three different concentrations of the culture filtrate were investigated using in vitro bioassays against the motile juvenile stage 2 of the root knot nematode Meloidogyne spp. Inactivation and mortality were recorded after 1, 3 and $24 \mathrm{hrs}$ of exposure to culture filtrates. The mortality of the root-knot nematode Meloidogyne-J2 after 24 hrs exposure to the culture filtrate was confirmed by rinsing with sterile distilled water that demonstrated the effects of the culture filtrate treatment were irreversible, as nematodes did not recover. Nematode mortality rates after 1 to $24 \mathrm{hr}$ exposure periods ranged from $80 \%$ to $100 \%$. The effects of the culture filtrates on root-knot nematode Meloidogyne-J2 increased with increasing culture filtrate concentration.
\end{abstract}

Keywords: Endophytic Fungi, Culturfiltrate, Root-knot Nematode, Meloidogyne spp., Nigrospora sp.

\section{Introduction}

Plant parasitic nematodes are responsible for over $\$ 100$ billion dollars in economic losses worldwide to a variety of crops. Root-knot nematodes are the most economically important group of plant parasitic nematodes worldwide, reducing both yield and crop quality $[20,12]$. Infected plants show growth of reduction, swollen roots which develop into the typical root-knot galls, are two, or three times larger in diameter as healthy root. Root-knot nematodes are very difficult to control because they are polyphagous, where its over 2000 plants species is a highly specialized and complex feeding relationship with their host [6]. The life cycle is almost completely confined inside the host plant and high reproductive capacity. Although chemical control is still a common method for reducing nematode population, there is a considerable public pressure to limit or even ban the use of nematicides. Many nematicides are highly toxic and sometimes very mobile in the soil because of their solubility in water.

Concern over these chemicals has led to an increased interest in biological control in order to achieve more environmentally friendly methods of reducing nematode damage.

The term endophyte was coined by Heinrich Anton De Bary in 1884 and it is referred to fungi that colonize internal plant tissues without causing any apparent symptoms to the host plant $[18,20]$. Fungal endophytes have been isolated from a great number of plants, such as bananas [14], maize [16], oilpalm [15], soybeans [8], potato [19,25] and tomato [3]. Endophytes are most often isolated from symptomless plants of various species [10]. Their association with

* Corresponding author:

Nur Amin (nuramin_62@yahoo.com) 
host plants is known to improve plant growth and vigor [26] and to potentially confer disease resistance in plants against pathogen infection [27].

The mechanisms of action responsible for nematode biocontrol mediated by endophytes are variable and include: the production of toxic secondary metabolites, competitive exclusion, competition for nutrients, predation, production of repellent compounds, alteration of root exudates, the induction of systemic resistance or a combination of these elements $[1,29,25,22,7,24]$.

\section{Materials and Methods}

\subsection{Source of Endophytic Fungi Nigrospora sp. Isolate RS 10}

Endophytic fungi Nigrospora sp. was originally isolated from cortical tissue of surface sterilized sengon root $P$. falcataria [17].

\subsection{Preparation of Culture Filtrate}

Pure fungal culture filtrate were obtained by centrifuging the fungal culture Nigrospora sp. isolate RS 10 in CzapekDox at $6000 \mathrm{rpm}$ for $10 \mathrm{~min}$ [11]. The resultant supernatant was aseptically transferred to sterile $25 \mathrm{ml}$ screw cap glass bottles and filtered through $0.22 \mu \mathrm{m}$ millipore membrane filters. The $\mathrm{pH}$ of the fungal filtrates was measured and the average $\mathrm{pH}$ calculated. Sterile distilled water $\left(\mathrm{H}_{2} \mathrm{O}\right)$ at $\mathrm{pH} \sim 7$ and uninoculated Capek-Dox whose $\mathrm{pH}$ was adjusted to level of the average $\mathrm{pH}$ of the fungal culturefiltrates were the two controls in the experiment. Culture filtrates were kept in the fridge at $4^{\circ} \mathrm{C}$ overnight.

\subsection{Source of Meloidogyne spp.}

The root-knot nematode Meloidogyne spp. was originally isolated from an infested field on tomato plant in distric Barombong, South Sulawesi, Indonesia. The extraction of Meloidogyne-J2 was obtained by using the modified extraction technique of Hooper et al. [5]. Roots were washed free from soil under tap water, cut into $1 \mathrm{~cm}$ pieces and macerated in a warring blender at high speed for $20 \mathrm{~s}$ and collected in a glass bottle. Sodium hypochloride $(\mathrm{NaOCl})$ was added to obtain a final concentration of $1.5 \%$ active Chlorine and the bottle was shaken vigorously for $3 \mathrm{~min}$. The suspension was then thoroughly washed with tap water through a sieve combination 250,100, 45 and $25 \mu \mathrm{m}$ mesh to remove the $\mathrm{NaOCl}$. Eggs were collected on the
$25 \mu \mathrm{m}$ sieve and then transferred to a glass bottle. The egg suspension was supplied with oxygen from an aquarium pump over 10 days to induce juvenile hatching. To separate active J2 from unhatched eggs or dead J2, a modified Baermann technique over 24 hours was used. The collected active J2 were adjusted to $1000 \mathrm{~J} 25 \mathrm{ml}-1$ and used immediately as source of inoculum.

\subsection{Investigation of Culture Filtrate Nigrospora sp. isolate RS 10 on Inactivation and Mortality of Meloidogyne-J2}

One milliliter of 2-wk-old undiluted culture filtrates transferred to $30-\mathrm{mm}$-diameter sterile glass petri dishes. The filtrates were inoculated with approximately 100 nematode of Meloidogyne-J2. Control petri dishes had pure Czapek-Dox inoculated with the nematode of Meloidogyne-J2. The investigation was laid in a completely randomized design on a laboratory bench. All investigation were repeated thrice over time, with three replicates per concentration. Inactivation and Mortality was determined by counting the number of active, inactive and dead nematode of Meloidogyne-J2 after 1, 3 and 24 hours of exposure to culture filtrate. Individual counts of each category were recorded for each time interval. The activity (mobility) of nematodes immersed in diluted culture filtrates was determined by counting the number of active and inactive nematodes after an exposure time of 1, 3 and $24 \mathrm{hrs.} \mathrm{After} 24$ hours, nematodes from each replication were rinsed with sterile distilled water after concentrating them using $28-\mu \mathrm{m}$ sieve and transferring them back into the petri dishes containing sterile distilled water. The petri dishes were left on the bench under laboratory conditions for extra 24 hours. Nematodes were probed with a fine needle under the microscope and those which were straight in shape and remained immotile even after probing were considered dead [14].

\subsection{Data Analysis}

Abott's corrected mortality formula was used to calculate nematode inactivation. Mortality was calculated as the percentage of mortalited nematodes out of the total original number of nematodes, at each time interval. Corrected inactivation and percentage mortality data was used to evaluate the effects of individual concentrations. Data were arcsine-square root transformed before analysis of variance (ANOVA). Laverne test was used to test for normality 
of distribution and homogeneity of variances. Analysis of Variance was carried to determine single factor effects and factor interactions. Where evident, effects of one factor were analysed at each time of the interacting factor. Effects of the factors were significant, means were separated using the Tukey's test.

\section{Result and Discussion}

\subsection{Result}

The percentage of inactivation nematodes by culture filtrates of Nigrospora sp. isolate RS 10 increased with an increase in filtrate concentration (Table 1). Differences in the percentage of inactivation nematodes as the culture filtrate concentration increased from $25 \%$ to $100 \%$ and significant difference $(\mathrm{P}<0.05)$. Culture filtrate concentration of $100 \%$ in 3 and 24 hours exposure reached $100 \%$ inactivation of nematode Meloidogyne-J2.

Percentage mortality of nematodes differed significantly among the different culture filtrate concentrations $(\mathrm{P}<0.005)$, and increased as the filtrate concentration increased(Figure 1). Significant differencesin thepercentage of dead nematodes were evident all of filtrate concentrations. In the culture filtrate of $100 \%$ and 24 hours exposure, followed by rinsing with distilled water still $100 \%$ nematode Meloidogyne-J2 dead.

\subsection{Discussion}

With increasing concentrations of culture filtrates of Nigrospora sp. isolates RS 10 increased the inacvtivation and the mortality of the nematodes. Culture filtrate at concentrations of $100 \%$ and $50 \%$ could be measured, a nearly $100 \%$ inactivation of the nematodes. Nur Amin [14] also noted a tendency depended the inactivation of the concentration at which he has examined Fusarium oxysporum A1 culture filtrates against burrowing nematode Radopholus similis. The same result reported Schuster [12] that inactivation of the nematode $P$. redivivus and $G$. Pallida depending on culture filtrate concentration. Cayrol and Djian [2] found in the culture filtrates of them studied by $F$. roseum var arthtosporioides at the concentrations of $50 \%$ and $100 \%$ after 24 hours of contact time a 100\% inactivation of M. arenaria-J2.

Hayashi et al. [4] also confirmed that a depending of the effect culture filtrate concentration of Irpex lacteus against the nematode Aphelenchoides besseyi. Even with Molina and Davide [13] the effect of the concentration was
Table 1. Percentage Inactivation of Meloidogyne-J2 in Different Culture filtrate Concentrations of Endophytic Nigrospora sp. isolate RS10 after 1, 3 and 24 hoursexposure

\begin{tabular}{lccc}
\hline \multicolumn{1}{c}{ CF } & \multicolumn{3}{c}{ Hours after Treatments } \\
Concentration & \multicolumn{1}{c}{ Inactivation(\%)Meloidogyne-J2 } \\
& 1 & 3 & 24 \\
\hline SDW & 7 & 7 & 10 \\
Czapeks-Dox & 12 & 14 & 18 \\
$100 \%$ & $80^{\mathrm{a}}$ & $100^{*}$ & $100^{*}$ \\
$50 \%$ & $61^{\mathrm{b}}$ & $80^{\mathrm{a}}$ & $95^{\mathrm{a}}$ \\
$25 \%$ & $52^{\mathrm{c}}$ & $67^{\mathrm{b}}$ & $84^{\mathrm{b}}$ \\
\hline
\end{tabular}

Means followed by the same letter (superscript) for each isolate in each bioassay are not significantly different at $\mathrm{P}=0.05$ according to Duncan's Multiple Range Test, $\mathrm{n}=3$; Czapeks-Dox as control media; *values could not be statistically calculated.

examined at 4 various fungal culture filtrates. Thus, at the concentrations of $50 \mathrm{ppm}$ or $200 \mathrm{ppm}$ of the culture filtrate of Penicillium oxalicum with $M$. incognita a mortality was determined by $13.5 \%$ and $78.6 \%$. For Meloidogyne-J2 in this investigation, a death rate of $45 \%$ and $100 \%$ respectively.

The use of diluted culture filtrates was intended to mimic the natural conditions encountered by root-knot Meloidogyne spp. in their host plants. As expected, the percentage immobilized nematodes decreased with a reduction in culture filtrate concentration. This is in agreement with findings by others regarding the effects of fungal filtrate concentrations on the immobilization of nematodes $[9,30]$. The low rates of nematode immobilization at low culture filtrate concentration might be due to the dilution of the toxic compounds. If the fungal isolates produce the toxins inside the plant, that concentration would probably be lower than in the bioassays conducted with undiluted culture filtrates. Thus, the levels of nematode control in the plants due to toxins can be expected to be lower than in the laboratory.

Production of toxins in the plant may, however, act as an additional form of armory that would help the plant guard it self from invasion by the nematode. Production of toxic metabolites in the plant by endophytes fungi Fusarium may inhibit not only nematode mobility, but also host searching and the infection processes [23]. While the production of toxic metabolites may be the main mechanism of action in the laboratory, the value of nematicidal compounds in the plant, and the mechanism where by endophytes protect host plants against root-knot nematode should be further investigated. 


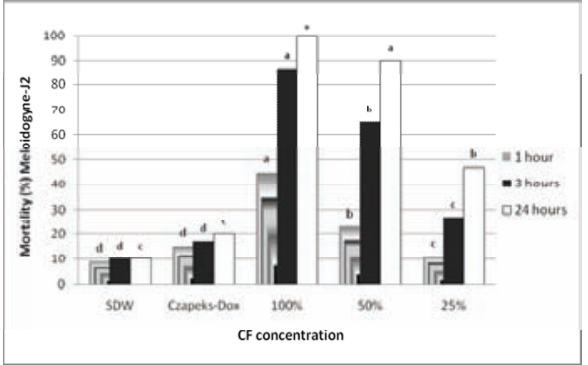

The numbers followed by the same letter (superscript) for each isolate in each bioassay are not significantly different at $\mathrm{P}=0.05$ according to Duncan's Multiple Range Test, $\mathrm{n}=3$; Czapeks-Dox as control media; * values could not be statistically calculated.

Figure 1. Percentage Mortality of Meloidogyne-J2 in Different Culture filtrate Concentrations of Endophytic Nigrospora sp. Isolate RS10 after 1, 3 and 24 hours exposure.

\section{Acknowledgement}

I am deeply thankful to the Minister of Education and Culture, Directorat General of Higher and Education (DIKTI), Directur of Research and Public Extension Service for providing fund for the current study, under the project of Hibah Bersaing.

\section{References}

1. Becker J O, Mejia T E et al. (1988). Effects of rhizobacteria on root-knot nematodes and gall formation, Phytopathology, vol 78, 1466-1469.

2. Cayrol J, and Djian, C. (1990). Etude de la toxicite de Fusarium roseum var arthrosporioides pour le nematode Meloidogyne arenaria, Comptes rendus de l'Académie d'agriculture de France, vol 76(8), 121-129.

3. Hallman J, and Sikora R A (1994). In vitro and in vivo control of Meloidogyne incognita with culture filtrates from non-pathogenic Fusarium oxysporum on tomato, Journal of Nematology, vol 26(1), 102.

4. Hayashi M, Wada K et al. (1981). New nematicidal metabolites from fungus, Irpex lactus, Agricultural Biology and Chemistry, vol 45(6), 1527-529.

5. Hooper D J, Hallmann J et al. (2005). Methods for extraction, processing and detection of plant and soil nematodes, Luc M, Sikora R A and Bridge J (Eds), Plant parasitic nematodes in subtropical and tropical Agriculture, CAB International, Wallingford, UK, 53-86.

6. Hussey R S, and Janssen G J W (2002). Plant resistance to parasitic nematodes, Root-knot nematodes: Meloidogyne species, Starr J L, Cook R, Bridge J (Eds.), CABI Publishing, 43-70.

7. Kiewnick S, and Sikora R A (2006). Biological control of the root-knot nematode Meloidogyne incognita by Paecilomyces lilacinus strain 251, Biological Control 38, 179-187.

8. Larran S, Rollán C et al. (2002). Endophytic fungi in healthy soybean leaves, Investigación Agraria: Producción y Protección de Vegetales, vol 17, No. 1, 173-177.

9. Mani A, and Sethi C L (1984). Some characteristics of culture filtrates of Fusarium solani toxic to Meloidogyne incognita, Nematropica, vol 14(2), 121-129.

10. McInroy J A, and Kloepper J W (1995). Survey of indigenous bacterial endophytes from cotton and sweet corn, Plant Soil, vol 173, 337-342, DOI: 10.1007/BF00011472

11. Meyer S L F, Massoud S I et al. (2000). Evaluation of Trichoderma virens and Bulkholderia cepacia for antagonistic activity against rootknot nematode, Meloidogyne incognita, Nematology, vol 2(8), 871-879.

12. Moens M, Perry R N et al. (2009). Meloidogyne species: a diverse group of novel and important plant parasites, Perry R N, Moens M, Starr J L (Eds.), Root-knot nemadodes, Wallingford, UK, CABI Publishing, 1-17.

13. Molina G C, and Davide R G (1986). Evaluation of microbial extracts for nematicidal activity against plant parasitic nematodes Meloidogyne incognita and Radopholus similes, The Phillipine Agriculturalist, vol 69, 173-186.

14. Amin N (1994). Untersuchungen über die Bedeutung endophytischer Pilze für die biologische Bekämpfung des wandernden Endoparasiten Radopholus similis (Cobb) Thorne an Bananen, PhD-Thesis, Bonn University.

15. Amin N, La Daha et al. (2008). The use of endophytic fungi to control of pest leaf borer Oryctes rhinoceros and Sexava sp. on oil palm plant, Research Report, Indonesian Ministry of Research and Technology.

16. Amin N, La Daha et al. (2011). Fungal endophyte as Biopesticide and Biofertilizer in Form of Tablet. Patent No. 00201100098.

17. Amin N (2012). Effect of rootexudates of Sengon (Paraserianthes falcataria L. Nielsen) inoculated with the fungal Endophyte Nigrospora sp. on control of the root-knot nematode Meloidogyne spp, Proceeding of International Conference on the Impacts of Climate Change to Forest Pests and Diseases in the Tropics, Jogyakarta, Indonesia.

18. Petrini O (1991). Fungal endophytes of tree leaves, Andrews J H, Hirano S S (Eds.), Microbial Ecology of Leaves, SpringerVerlag, NY, 179-187.

19. Racke J, and Sikora R A (1992). Isolation, formulation and antagonistic activity of rhizobacteria toward the potato cyst 
nematode Globodera Pallida, Soil Biology \& Biochemistry, vol 24(6), 521-526.

20. Sasser J N, and Freckman D W (1987). A world perspective on nematology: the role of the society, Veech J A, Dickson D W (Eds), Vistas on nematology: a commemoration of the twenty-fifth anniversary of the society of nematologists, $7-14$.

21. Schuster R-P (1992). Untersuchungen zur biologischen Bekämpfung des Kartoffelzysten-nematoden Globodera pallida (Stone) mit eipathogenen Pilzen unter Berücksichtigung von deren Wirkungsweise sowie biotischen und abiotischen Faktoren. Diss, Bonn.

22. Siddiqui I A, and Shaukat S S (2003). Endophytic bacteria: prospects and opportunities for the biological control of plant-parasitic nematodes, Nematologia Mediterranea, vol 31, 111-120.

23. Sikora R A, Niere B et al. (2003). Endophytic microbial diversity and plant nematode management in African Agriculture, Neuenschwander P, Borgemeister C and Langewald J (Eds), Biological control in IPM systems in Africa, CAB International. Wallingford, 179-192.

24. Sikora RA, Schafer K et al. (2007). Modes of action associated with microbially induced in planta suppression of plant-parasitic nematodes, Australasian Plant Pathology, vol 36(2), 124-134.
25. Sturz A V, Christie B R et al. (1999). Endophytic bacterial communities in the periderm of potato tubers and their potential to improve resistance to soil-borne plant pathogens, Plant Pathology, vol 48, 360-369.

26. Ting A S Y , Meon S et al. (2008). Endophytic microorganisms as potential growth promoters of banana, BioControl, vol 53(3), 541-553. DOI: 10.1007/s10526-0079093-1.

27. Ting A S Y, Meon S et al. (2007). Field evaluation of nonpathogenic Fusarium oxysporum isolates UPM31P1 and UPM39B3 for the control of Fusarium wilt in 'Pisang Berangan' (Musa, AAA), Proceeding of the International Symposium on Recent Advances in Banana Crop Protection for Sustainable Production and Improved Livelihoods, ISHS Acta Horticulturae, 139-144.

28. Wilson D (1995). Fungal endophytes which invade insect galls: insect pathogens, benign saprophytes, or fungal inquilines?, Oecologia, vol 103, 255-260.

29. van Loon L C, van Bakker P A H M, Pieterse C M J (1998). Systemic resistance induced by rhizosphere bacteria, Annual Review of Phytopathology, vol 36, 453-483.

30. Zareen A, Siddiqui I A et al. (2001). Observations on the nematicidal effect of Fusarium solani on the root-knot nematode Meliodogyne javanica, Journal of Plant Pathology, vol 83, No. 3, 207-214. 